\title{
Factors contributing to the perception of facial asymmetry in dentists and laypersons
}

\author{
Sung-Kwon Choi ${ }^{1}$, Kyung-Hwa Kang ${ }^{2 *}$ \\ ${ }^{1}$ College of Dentistry, Graduate School of Wonkwang University, Iksan, Korea \\ ${ }^{2}$ Department of Orthodontics, College of Dentistry, Wonkwang University, Iksan, Korea
}

The aims of this study were to find differences in how dentists and laypersons evaluate facial asymmetry and to identify factors contributing to the perception of asymmetry. Photographs of young male and female faces were transformed according to lower facial height, lower facial width, the direction of chin deviation, and the angle of chin deviation. Thirty dentists (mean age, 28.0 years; 16 males, 14 females) and 50 laypersons (mean age, 22.2 years; 24 males, 26 females) answered a questionnaire evaluating the asymmetry in 24 photographs (12 males and 12 females) using visual analog scale. The individual t-test and logistic regression analysis were used for statistical analysis. There was no difference between dentists and laypersons in evaluating photographs with a $5^{\circ}$ chin deviation angle. Compared with laypersons, dentists evaluated photographs with $10^{\circ}$ chin deviation angle as more asymmetric. Faces with a long lower facial height, left deviation of the chin, and a large chin deviation angle were considered to be more asymmetric than those with normal lower facial height, right deviation of the chin, and a small chin deviation angle, respectively $(p<0.05)$. There was no consistent relationship between lower facial width and the perception of facial asymmetry in both the groups. The perception of facial asymmetry was affected by lower facial height, the direction of chin deviation, and the amount of chin deviation.

Key Words: Facial asymmetry, Perception, Visual analog scale

ㄷ) This is an open-access article distributed under the terms of the Creative Commons Attribution Non-Commercial License (http://creativecommons.org/licenses/by-nc/4.0) which permits unrestricted noncommercial use, distribution, and reproduction in any medium, provided the original work is properly cited.

\section{서 론}

얼굴의 대칭성은 사람의 매력을 결정짓는 중요한 요소 중 하 나로, 얼굴이 대칭적일수록 유전적으로 우월한 것으로 인식된 다[1-4]. 사람에서 완벽한 대칭성은 찾아보기 힘들며 심미적으 로 보이는 사람일지라도 어느 정도의 안면 비대칭은 가지고 있 다[4-9].

안면 비대칭은 비대칭적인 동공의 위치, 비뚤어진 코, 하악 하 연의 비대칭과 같이 다양한 요소들의 영향을 받는다. 그 중 하안
면 부위는 상안면 부위에 비해 비대칭 경향이 크고[9,10], 상하 악 복합체의 위치 또는 형태가 수술을 통해 바뀔 수 있기 때문에 안면 비대칭의 평가 및 치료계획 수립에 있어 중요한 부분을 차 지한다.

안면 비대칭에 관한 연구는 대부분 안면 비대칭의 해부학적 인 특성에 집중되어 있으며 해부학적인 특성과 비대칭의 인식 간의 상관관계에 관한 연구는 많지 않다. 이부의 편위는 비대칭 의 인식에 영향을 미치는 주요한 요인 중 하나로 일반인의 경우 $5.6 \mathrm{~mm}$ 의 이부의 편위를 비대칭으로 인식하는 것으로 나타났

Received May 13, 2019; Revised June 29, 2019; Accepted July 8, 2019

Corresponding author: Kyung-Hwa Kang, Department of Orthodontics, Wonkwang University Dental Hospital, 895 Muwang-ro, Iksan 54538, Korea.

Tel: +82-63-859-2962, Fax: +82-63-857-4002, E-mail: pigtail@wku.ac.kr

Copyright @ 2019, Oral Biology Research Institute 
다[11]. 임상사진을 이용한 Lee 등[12]의 연구에 따르면 이부의 편위 이외에도 입술의 경사, 하악체 경사도 차이(body inclination difference), 하악각 경사도 차이(gonial angle difference) 가 안면 비대칭의 인지에 영향을 준다고 하였다.

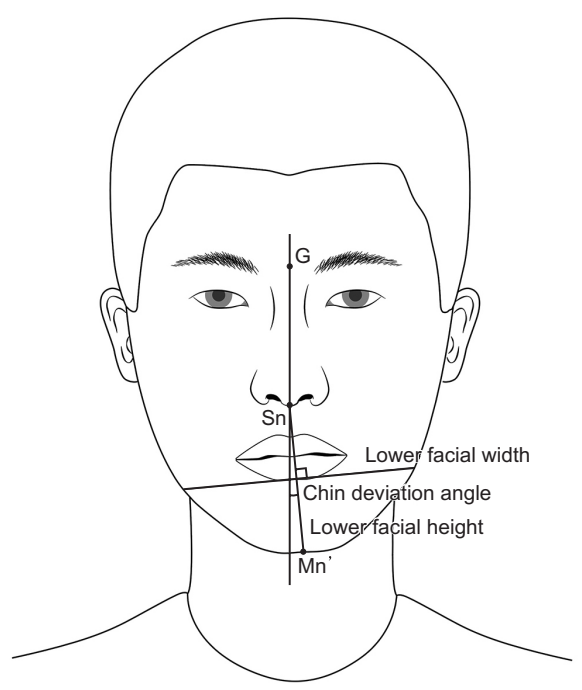

Fig. 1. Soft tissue landmarks and reference lines used in morphing. G, glabella; Sn, subnasale; Mn', soft tissue menton; vertical reference line, line from $\mathrm{G}$ to $\mathrm{Sn}$; lower facial length, the length from $\mathrm{Sn}$ to $\mathrm{Me}$; lower facial width, the length between points where perpendicular bisector of line from $\mathrm{Sn}$ to Me and the outline of face meet.
안면 비대칭은 해부학적 비대칭의 정도뿐만 아니라 평가자 집단에 따라서도 다르게 인지될 수 있음이 보고된 바 있다. 일반 인들은 미약한 안면 비대칭을 정상으로 평가하는 경향을 보이 며, 치과의사들은 일반인에 비해 안면 비대칭을 인지하는 역치 가 낮은 것으로 보고되었다[11,13].

본 연구에서는 안모사진을 변형시켜 얻은 비대칭 사진을 바 탕으로 이부의 편위량 외에 안면 비대칭의 인식에 영향을 미치 는 다른 요인들을 알아보고 비대칭의 인식에서 치과의사와 일 반인 사이에 차이가 있는지를 확인하고자 한다.

\section{대상 및 방법}

\section{비대칭 사진 만들기}

원광대학교 치과대학병원의 IRB의 승인(IRB no. WKDIRB201509-01) 이후 정상교합을 보이는 2명의 젊은 성인 남 녀(남 23세, 여 22세)를 자연 두부 위치로 유도한 뒤, 디지털 카 메라(D5300; Nikon, Tokyo, Japan)를 이용하여 사진을 촬영 하였다. 촬영된 사진을 Photoshop CC (Adobe systems, San Jose, $\mathrm{CA}, \mathrm{USA}$ )를 이용하여 좌우 대칭이 되도록 하여 기본 이미 지를 만들었다.

기본 이미지를 다음의 계측점과 기준선을 이용하여 변형시켰 다: 하안면 고경, subnasale ( $\mathrm{Sn}$ )부터 연조직 menton (Me')까
A

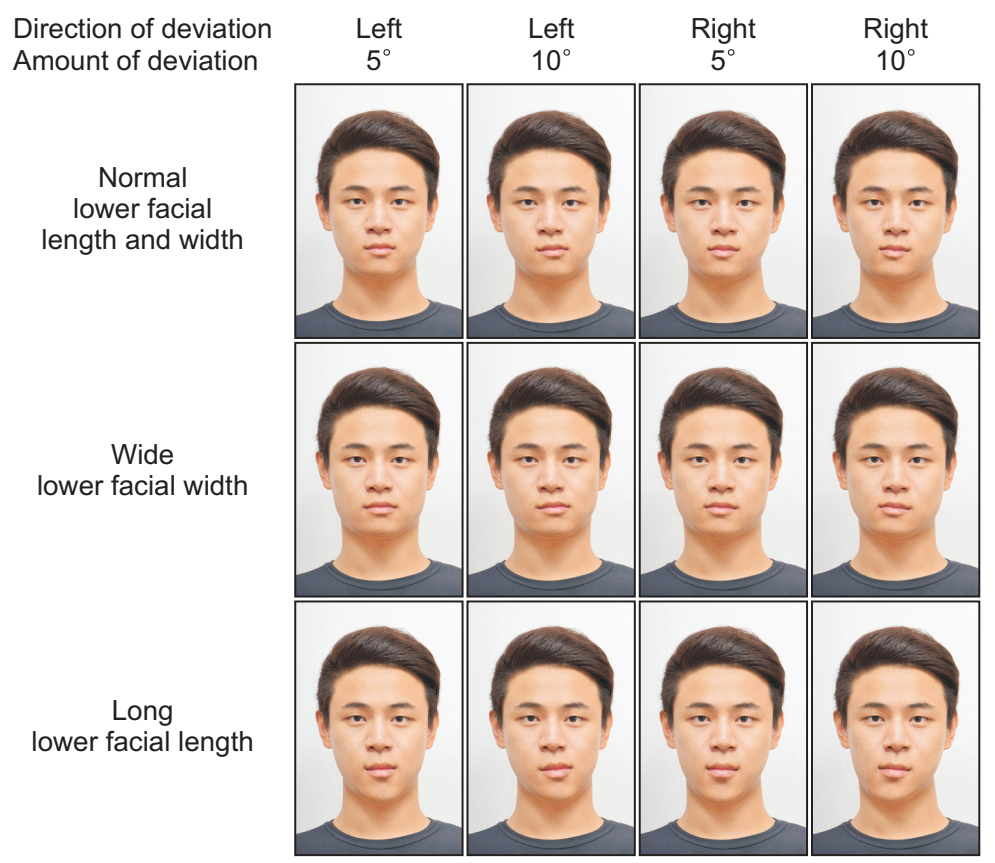

B

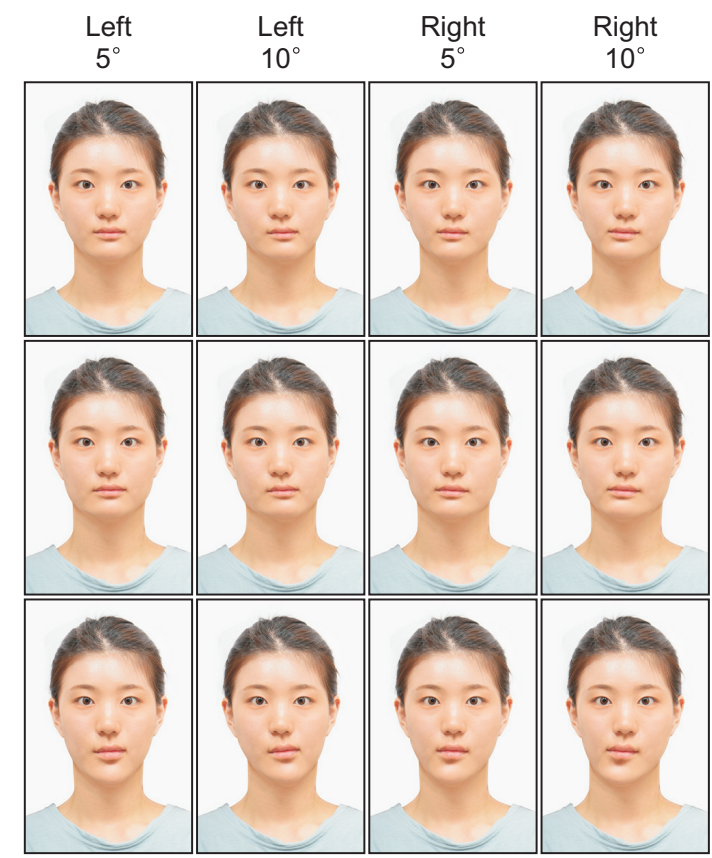

Fig. 2. Photographs of (A) male and (B) female faces with various degrees of facial asymmetry. 
지의 거리; 하안면 폭경, $\mathrm{Sn}$ 과 $\mathrm{Me}$ 를 잇는 선분의 수직이등분선 이 하악 외연과 만나는 점들 간의 거리; 이부 편위각, 수직 기준 선과 $\mathrm{Sn}-\mathrm{Me}$ '가 이루는 각(Fig. 1). 사진에 따라 하안면 고경과 하안면 폭경을 기본 이미지에서 각각 $1 / 6$ (남자사진에서 11.3 $\mathrm{mm}$, 여자사진에서 $10.3 \mathrm{~mm}$ ), 1/10 (남자사진에서 $10.8 \mathrm{~mm}$, 여자사진에서 $8.2 \mathrm{~mm}$ )씩 증가시켰으며, 이부 편위각은 좌측 혹 은 우측으로 각각 $5^{\circ}$ 에서 $10^{\circ}$ 로 설정하였다. 이 같은 과정을 거 쳐 총 24 장의 비대칭 사진을 만들었다.

변형된 사진을 $\mathrm{A} 4$ 용지에 실제 크기로 인화하여 무작위적으로 배열한 뒤 남자사진과 여자사진이 번갈아 오도록 하여 사진첩 을 제작하였다(Fig. 2).

\section{설문지 제작과 설문조사}

30 명의 치과의사(원광대학교 치과대학병원에 근무중인 전공 의, 평균연령 $28.0 \pm 3.5$ 세; 남자 16 명, 여자 14 명)와 50 명의 일 반인(평균연령 22.2 \pm 2.9 세; 남자 24명, 여자 26명)을 대상으로 설문조사를 실시하였다. 각 평가자들은 사진첩과 visual analog scale (VAS)을 답할 수 있는 설문지를 받았다. 설문지 바의 왼쪽 $1 / 3$ 은 수술을 필요로 하지 않는 경미한 비대칭, 중간 $1 / 3$ 은 수 술을 필요로 하지 않은 중등도 비대칭, 오른쪽 $1 / 3$ 은 수술을 필 요로 하는 심한 비대칭을 의미하는 것으로 설명하였다(Fig. 3). 평가자들에게는 사진을 서로 대조해보지 말고 1 분 내에 답하도 록 지시하였다.

\section{통계 분석}

SPSS Statistics ver. 12.0 (SPSS Inc., Chicago, IL, USA)을 이 용해 독립 t검정과 로지스틱 회귀분석이 통계적 분석을 위해 사 용되었다. 독립 $\mathrm{t}$ 검정은 변수들과 평가자에 따라 유의한 차이를 보이는지를 확인하기 위해 사용되었다. 로지스틱 회귀분석을 위해 3개의 변수(하안면 고경, 하안면 폭경, 이부의 편위 방향) 와 치료의 필요성을 0 또는 1 로 구분하였다. 긴 하안면 고경, 넓
은 하안면 폭경, 좌측 이부 편위, $66.66 \mathrm{~mm}$ 를 넘는 VAS 응답이 1 로 변환되었으며 정상 하안면 고경, 정상 하안면 폭경, 우측 이 부 편위, 66.66 이하의 VAS 응답은 0으로 변환되었다. 로지스틱 회귀분석은 $5^{\circ}$ 와 $10^{\circ}$ 도 이부 편위각에서 각각 평가되었다. $\mathrm{p}$ 값 이 0.05 미만인 경우 통계적 유의성을 갖는 것으로 평가하였다. 측정 오차는 Dahlberg 공식; $D=\sqrt{\sum \frac{d^{2}}{2 N}}$ 을 통해 계산하였다. 여기서 $\mathrm{d}$ 는 최초 측정치와 2 주 뒤 측정치 간의 차이를 의미하며 $\mathrm{N}$ 은 표본 수를 의미한다. 측정오차는 $0.07 \mathrm{~mm}$ 였다.
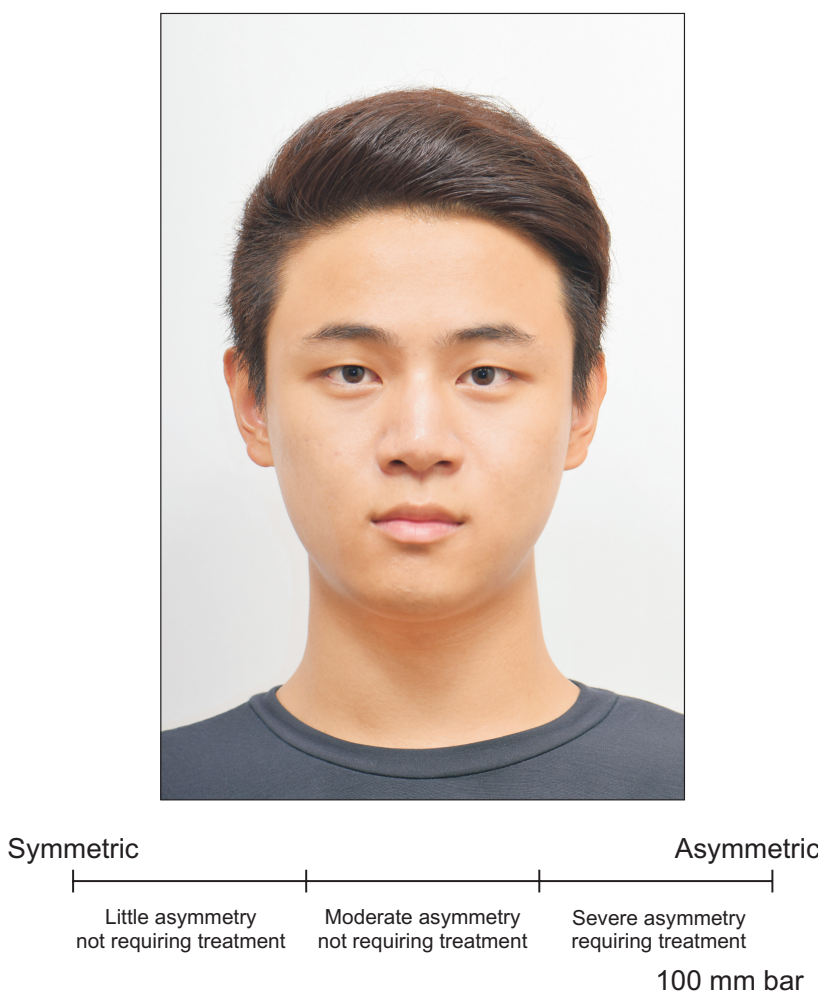

Fig. 3. The process of the survey. Twenty-four photographs were evaluated by visual analog scale in turn. A $100 \mathrm{~mm}$ bar was divided into three parts which means the severity of facial asymmetry.

Table 1. Comparison of mean visual analog scale scores by factors including lower facial height, lower facial width, direction of deviation in $5^{\circ}$ and $10^{\circ}$ of chin deviation angle

\begin{tabular}{|c|c|c|c|c|c|c|c|c|c|c|}
\hline & & \multicolumn{3}{|c|}{ Lower facial height } & \multicolumn{3}{|c|}{ Lower facial width } & \multicolumn{3}{|c|}{ Direction of deviation } \\
\hline & & Long & Normal & $p$-value & Wide & Normal & $p$-value & Right & Left & $p$-value \\
\hline \multirow[t]{2}{*}{$5^{\circ}$} & Dentists & 50.06 & 34.56 & $0.000^{c}$ & 40.81 & 34.56 & $0.033^{\mathrm{a}}$ & 34.91 & 48.71 & $0.000^{c}$ \\
\hline & Laypersons & 49.60 & 34.08 & $0.000^{c}$ & 45.20 & 34.08 & $0.000^{c}$ & 38.17 & 47.75 & $0.000^{c}$ \\
\hline \multirow[t]{2}{*}{$10^{\circ}$} & Dentists & 83.76 & 68.88 & $0.000^{c}$ & 59.63 & 68.88 & $0.000^{c}$ & 66.70 & 74.81 & $0.000^{c}$ \\
\hline & Laypersons & 79.40 & 62.90 & $0.000^{\mathrm{c}}$ & 57.11 & 62.90 & $0.006^{\mathrm{b}}$ & 63.06 & 69.88 & $0.000^{c}$ \\
\hline
\end{tabular}

Independent t-test, ${ }^{\mathrm{a}} p<0.05 ;{ }^{\mathrm{b}} p<0.01 ;{ }^{\mathrm{c}} p<0.001$. 


\section{결 과}

\section{안면비대칭의 인지에 영향을 미치는 요소들과 그 영향}

같은 이부 편위각에서 긴 하안면 고경을 가진 사진이 정상 하 안면 고경을 가진 사진에 비해 더욱 비대칭적으로 인식되었으 며, 좌측으로 편위된 이부는 우측 편위된 경우보다 더욱 비대칭 적으로 인식되었다 $(p<0.001)$. 정상보다 넓은 하안면 폭경을 가진 사진은 이부 편위각이 $5^{\circ}$ 일 때는 더욱 비대칭적으로 인식 된 반면 $10^{\circ}$ 일 때는 오히려 덜 비대칭적인 것으로 인식되었다 (Table 1).

안면 비대칭의 치료 필요성에 대한 응답에서도 긴 하안면 고 경과 하악의 좌측 편위를 동반한 비대칭 안모의 경우 치료가 필 요하다고 응답한 비율이 높게 나타났다(Table 2).

\section{치과의사와 일반인의 안면비대칭의 인지 비교}

$5^{\circ}$ 의 이부 편위각을 가진 사진에서 치과의사와 일반인이 느끼 는 안면 비대칭의 정도에는 차이가 없었으며, 대부분 치료가 필 요하지 않은 비대칭으로 평가하였다. 치과의사는 $10^{\circ}$ 의 이부 편 위각을 가진 사진에 대해 일반인보다 더욱 수술적인 치료가 필
요한 것으로 인지하였다(Table 3).

\section{고 찰}

현재까지 보고된 많은 연구들이 이부의 편위가 안면 비대칭 의 인지에 미치는 영향에 집중하고 있다. 이번 연구는 안면 비대 칭의 인식에 영향을 미치는 다른 요소들을 확인하는 것이었다.

안모 비대칭의 인식을 조사하기 위한 방법으로, Lee 등[12]은 치료 전 환자 사진을 그대로 이용하였으며, McAvinchey 등[11] 과 Meyer-Marcotty 등[14]은 삼차원 이미지를 변형하여 이용 하였다. 삼차원 이미지를 사용한 실험의 경우 얼굴 부분만 노출 시켰기 때문에 머리카락과 같은 얼굴 이외의 조건에 영향을 받 지 않는다는 장점은 있으나 우리가 일상적으로 바라보는 얼굴 의 모습과는 이질적일 수 있다. 본 연구에서는 최대한 일상적으 로 볼 수 있는 얼굴의 모습을 재현하기 위해 머리카락 부위와 어 깨의 일부까지 사진에 포함시켰다.

이번 연구에서는 이부의 편위뿐만 아니라, 하안면 고경과 하 안면 폭경도 비대칭의 인지에 영향을 미칠 것으로 가설을 세웠 으며 $\mathrm{Sn}$ 과 $\mathrm{Me}$ 가 하안면 고경을 측정하는 계측점으로 활용되었 다. 연조직 gonion의 경우 측정에 다소 모호함이 있어서 $\mathrm{Sn}$ 과 $\mathrm{Me}$ '를 이은 선분의 수직 이등분선을 활용하여 하안면 폭경을

Table 2. Odds ratio of factors affecting the need for surgery

\begin{tabular}{lccccc}
\hline & \multicolumn{3}{c}{$\mathbf{5}^{\circ}$} & & $\mathbf{1 0}^{\circ}$ \\
\cline { 2 - 6 } & OR $(\mathbf{9 5 \%} \mathbf{C I})$ & p-value & OR (95\% CI) & p-value \\
\hline Long lower facial height & $5.23(3.11-8.77)$ & $0.000^{\mathrm{b}}$ & & $5.61(3.75-8.40)$ & $0.000^{\mathrm{b}}$ \\
Wide lower facial width & $3.95(2.34-6.69)$ & $0.000^{\mathrm{b}}$ & & $0.57(0.42-0.79)$ & $0.001^{\mathrm{a}}$ \\
Left deviation of chin & $3.35(2.31-4.87)$ & $0.000^{\mathrm{b}}$ & & $2.12(1.59-2.83)$ & $0.000^{\mathrm{b}}$ \\
\hline
\end{tabular}

OR, odds ratio; $\mathrm{CI}$, confidence interval.

Logistic regression analysis, ${ }^{\mathrm{a}} p<0.01 ;{ }^{\mathrm{b}} p<0.001$.

Table 3. Comparisons of mean visual analogue scale scores between dentists and laypersons

\begin{tabular}{|c|c|c|c|c|c|c|}
\hline & \multicolumn{3}{|c|}{$5^{\circ}$} & \multicolumn{3}{|c|}{$10^{\circ}$} \\
\hline & Dentists & Laypersons & $p$-value & Dentists & Laypersons & $p$-value \\
\hline \multicolumn{7}{|c|}{ Lower facial height } \\
\hline Long & 50.06 & 49.60 & 0.862 & 83.76 & 79.40 & $0.006^{\mathrm{a}}$ \\
\hline Normal & 34.56 & 34.08 & 0.845 & 68.88 & 62.90 & $0.004^{\mathrm{a}}$ \\
\hline \multicolumn{7}{|c|}{ Lower facial width } \\
\hline Wide & 40.81 & 45.20 & 0.112 & 59.63 & 57.11 & 0.317 \\
\hline Normal & 34.56 & 34.08 & 0.845 & 68.88 & 62.90 & $0.004^{\mathrm{a}}$ \\
\hline \multicolumn{7}{|c|}{ Direction of deviation } \\
\hline Right & 34.91 & 38.17 & 0.114 & 66.70 & 63.06 & 0.072 \\
\hline Left & 48.71 & 47.75 & 0.672 & 74.81 & 69.88 & $0.005^{\mathrm{a}}$ \\
\hline
\end{tabular}

Independent t-test, ${ }^{a} p<0.01$. 
구하였다.

본 실험을 통해 같은 이부 편위각을 가진 얼굴에서도 하안면 의 고경에 따라 안면 비대칭이 다르게 인식될 수 있음을 확인하 였다. 증가된 하안면 고경이 안면 비대칭의 인식정도를 증가시 킨다면, 하안면의 고경을 줄이는 이부 성형술이 안면비대칭의 완화에 도움을 줄 수도 있을 것이다.

하안면의 폭도 안면 비대칭의 인식에 영향을 주긴 하였으나 그 효과가 이부 편위각에 따라 다르게 나타났기 때문에 일관된 결론을 얻을 수 없었으며, 하안면 폭경의 효과를 확인하기 위해 서는 추가적인 연구가 필요해 보인다.

앞선 연구들에서 안면 비대칭의 인지에 영향을 미치는 요소 로 입술의 경사를 지목하였다. 입술의 경사는 하악골의 편위와 관련되어 나타나는 경우가 많기 때문에 본 연구에서는 입술의 경사를 종속적인 변수로 판단하였으며 따로 변수로 포함시키지 않았다. 본 연구에서는 최대한 자연스럽고 일반적인 안면비대 칭 상황을 연출하기 위해 입술의 경사는 이부의 편위 방향과 정 도에 따라 점진적으로 변형시켰다. 따라서 설문 결과에서 입술 의 영향을 완전히 배제할 수는 없으며 이부의 편위와 입술의 경 사에 의한 효과가 같이 나타났다고 보는 것이 타당하다.

이부의 좌측 편위는 우측 편위보다 더욱 비대칭적으로 인지 되었다. 이러한 결과는 앞선 연구와 일치되지 않았다. MeyerMarcotty 등[14]은 이부의 우측 편위가 좌측 편위보다 더욱 비 대칭적으로 인지된다고 한 반면, McAvinchey 등[11]은 이부의 좌우측 편위 방향이 비대칭의 인지에 영향을 미치지 않는다고 하였다. 편위 방향에 따른 효과를 해석하는 데 있어 연구들마다 차이를 보이는 만큼 정확한 결론을 내기 위해서는 추가적인 연 구가 필요해 보인다.

평가자 집단에 따른 안면 비대칭의 인식에 관한 연구에서 McAvinchey 등[11]과 Jackson 등[13]은 치과의사가 일반인 에 비해 비대칭을 좀 더 민감하게 인식한다고 보고하였으나, Meyer-Marcotty 등[14]의 연구에서는 안면 비대칭을 인식하 는 데 있어 일반인과 전문가(교정과 의사, 구강악안면외과 의사) 사이에 차이가 없다고 하였다. 본 연구에서는 $5^{\circ}$ 의 이부 편위각 에서는 일반인과 치과의사 사이에 유의한 차이가 나타나지 않 았으며, $10^{\circ}$ 의 이부 편위각에서는 치과의사가 일반인에 비해 더 비판적으로 안면 비대칭을 인식하는 것으로 나타났다.

본 연구를 포함하여 현재까지 이루어진 대부분의 연구들은 설문 대상을 전문가 집단과 일반인으로 하였으며, 안면 비대칭 치료를 원하는 환자들이 안면 비대칭을 어떻게 인지하는지에 대한 연구는 부족하다. 외모를 주소로 내원한 악교정수술 환자 의 경우 임상가와 마찬가지로 안면 비대칭을 민감하게 인식한 다는 보고[15]가 있는 만큼 안면 비대칭을 가진 환자들이 느끼 는 안면 비대칭의 정도를 이해하기 위해서는 이들을 대상으로
한 연구도 필요해 보인다.

결론적으로 다음과 같은 사실을 이번 연구를 통해 알 수 있었 다. 1. 치과의사는 경도의 안면 비대칭을 인지하는 데 있어 일반 인과 차이를 보이지 않으나, 심한 안면비대칭에 대해서는 일반 인보다 더욱 비판적으로 인식한다. 2. 같은 이부 편위각을 보이 는 얼굴에서 하안면 고경이 길수록 더 비대칭적으로 인지된다. 3. 이부의 좌측 편위는 우측 편위보다 더욱 비대칭적으로 인지 된다.

\section{CONFLICTS OF INTEREST}

The authors declare that they have no competing interests.

\section{ORCID}

\author{
Sung-Kwon Choi \\ https://orcid.org/0000-0001-9546-9837 \\ Kyung-Hwa Kang \\ https://orcid.org/0000-0002-4263-1084
}

\section{REFERENCES}

1. Kowner R. Facial asymmetry and attractiveness judgment in developmental perspective. J Exp Psychol Hum Percept Perform 1996;22:662-675. doi: 10.1037/00961523.22.3.662.

2. Grammer K, Thornhill R. Human (Homo sapiens) facial attractiveness and sexual selection: the role of symmetry and averageness. J Comp Psychol 1994;108:233-242. doi: 10.1037/0735-7036.108.3.233.

3. Jones BC, Little AC, Penton-Voak IS, Tiddeman BP, Burt DM, Perrett DI. Facial symmetry and judgements of apparent health: Support for a "good genes" explanation of the attractiveness-symmetry relationship. Evol Hum Behav 2001;22:417-429. doi: 10.1016/S1090-5138(01)00083-6.

4. Sforza C, Laino A, Gaia G, Luca P, Ferrario VF. Three dimensional facial asymmetry in attractive and normal people from childhood to young adulthood. Symmetry 2010;2:1925-1944. doi: 10.3390/sym2041925.

5. Bishara SE, Burkey PS, Kharouf JG. Dental and facial asymmetries: a review. Angle Orthod 1994;64:89-98. doi: 10.1043/0003-3219(1994)064〈0089:DAFAAR〉2.0.CO;2.

6. Peck S, Peck L, Kataja M. Skeletal asymmetry in esthetically pleasing faces. Angle Orthod 1991;61:43-48. doi: 10.1043/0003-3219(1991)061〈0043:SAIEPF〉2.0.CO;2.

7. Ercan I, Ozdemir ST, Etoz A, Sigirli D, Tubbs RS, Loukas M, Guney I. Facial asymmetry in young healthy subjects eval- 
uated by statistical shape analysis. J Anat 2008;213:663669. doi: 10.1111/j.1469-7580.2008.01002.x.

8. Haraguchi S, Iguchi Y, Takada K. Asymmetry of the face in orthodontic patients. Angle Orthod 2008;78:421-426. doi: 10.2319/022107-85.1.

9. Hwang HS, Yuan D, Jeong KH, Uhm GS, Cho JH, Yoon SJ. Three-dimensional soft tissue analysis for the evaluation of facial asymmetry in normal occlusion individuals. Korean J Orthod 2012;42:56-63. doi: 10.4041/kjod.2012.42.2.56.

10. Severt TR, Proffit WR. The prevalence of facial asymmetry in the dentofacial deformities population at the University of North Carolina. Int J Adult Orthodon Orthognath Surg 1997;12:171-176.

11. McAvinchey G, Maxim F, Nix B, Djordjevic J, Linklater R, Landini $\mathrm{G}$. The perception of facial asymmetry using 3-dimensional simulated images. Angle Orthod 2014;84:957965. doi: 10.2319/120213-888.1.

12. Lee MS, Chung DH, Lee JW, Cha KS. Assessing soft-tissue characteristics of facial asymmetry with photographs. Am J Orthod Dentofacial Orthop 2010;138:23-31. doi: 10.1016/ j.ajodo.2008.08.029.

13. Jackson TH, Mitroff SR, Clark K, Proffit WR, Lee JY, Nguyen TT. Face symmetry assessment abilities: clinical implications for diagnosing asymmetry. Am J Orthod Dentofacial Orthop 2013;144:663-671. doi: 10.1016/ j.ajodo.2013.06.020.

14. Meyer-Marcotty P, Stellzig-Eisenhauer A, Bareis U, Hartmann J, Kochel J. Three-dimensional perception of facial asymmetry. Eur J Orthod 2011;33:647-653. doi: 10.1093/ ejo/cjq146.

15. Naini FB, Donaldson AN, McDonald F, Cobourne MT. Assessing the influence of asymmeftry affecting the mandible and chin point on perceived attractiveness in the orthognathic patient, clinician, and layperson. J Oral Maxillofac Surg 2012;70:192-206. doi: 10.1016/j.joms.2010.12.055. 